\title{
The Role of Internet Penetration on Online Opportunity Search among the Youths in Rwanda
}

\author{
Oluwaseun David Adepoju, Tofik Saad, Sanelisiwe Manana \\ ALU Rwanda
}

\begin{abstract}
The world was never the same since the internet became mainstream in 1993. This global wonder has disrupted a lot of human activities in myriads of ways that we cannot begin to measure. However, the level of penetration and use varies across countries of the world. In lieu of this varying nature in penetration and use, this study examined the role of internet penetration on opportunity search by young people in Rwanda. This is an expository research of methodological triangulation. Qualitative data were collected through the use of a questionnaire for 100 randomly selected Rwandan youth and guided interviews were conducted for 10 selected undergraduate students of the African Leadership University in Kigali, Rwanda. The result shows that most of the respondents are between the ages of 20-29 years with $86 \%$ representation. $70.7 \%$ of the respondents noted that internet penetration has helped Rwanda in giving access to valuable re-usable data. A high $76.6 \%$ of the respondents noted that the internet has given them foreign university admission and research articles online. This is indicative of the fact most young people between the ages of 20 and 29 years old are most likely students in universities. In this study, $55.2 \%$ of the respondents disagreed that there are more opportunities offline which invariably means that they believe that there are more opportunities online than offline. $78.1 \%$ of the respondents spend 5 hours and above daily on the internet. The respondent's priorities online seemed to show in their responses as a higher percentage of $87.4 \%$ stated that they are either listening to music or browsing social media most times when they are online. A higher percentage of the respondents, $75.5 \%$ chose LinkedIn to be their go to website for opportunities. The study concluded by making policy recommendations such as digital diplomacy, open data, and electronic government policies.
\end{abstract}

\section{Introduction}

In the era where the internet has broken boundaries of ideological and physical walls, opportunities search has become multifarious and no longer a matter of territorial immediateness. Netizens are becoming vast in their search for opportunities all around the world even though seated in just one corner of the world. It has become imperative in the 21 st century to become global in opportunity search because of the enormous provisions brought by the internet. In the past, before the penetration of the internet in Africa, information access was limited, and people's awareness of global opportunities was predominantly institutional. Access to information was restricted to one's physical jurisdiction and lucky were you if another fellow human shared useful information with you. In a nutshell, information access was as far as you could search and ask in the physical space. The current situation is now a matter of how broad you can search and no longer how much information is available. The world has even transitioned from the period of information scarcity to information explosion. Opportunities are no longer scarce and are now a click away because of internet penetration. The rate at which people get jobs, university admissions, conference travels, vacations, fellowships and a whole lot of other opportunities is amazing. It calls for critical analysis and comparison with what it mean sto access opportunities offline these days. It is also pertinent to ask if there are some opportunities that can never be accessed online even though there is high internet penetration. In lieu of this, this study aims to crossexamine the role of the internet in opportunity search among the youths of Rwanda and what they are doing online. It will critically analyze if offline opportunities are still very popular and relevant in the internet ravaged age that we are. 


\section{Research Questions}

The overall question of this study is to ask the role of internet penetration on the search of opportunities amongst youths. The question was asked with the following specific questions:

1. What are the advantages of Internet penetration in Rwanda?

2. What are the opportunities you have obtained online through the use of the internet?

3. Between online and offline channels, which have more opportunities?

4. What are the major activities young people in Rwanda engaged in?

\section{Literature Review}

This literature review employed the funnel approach as there are scarcity of literatures on internet penetration in the location of study which attests to the importance of this study as being novel. There is a large of pool of reports and studies on internet penetration globally and Rwanda deserves more visibility in these reports more than ever before. A lot of amazing things have been happening in this beautiful East African country due to internet penetration and is is worthy of note what the younger generation have been doing with the internet.

Wei [5] defined Internet penetration rate as the percentage of Internet users divided by populations for each country. He also went further to define an Internet user as being over 16 years old and uses the Internet on a regular or occasional basis in businesses and homes. Wei's definition of an internet user seemed to put a benchmark of an acceptable age to be on the internet without being vulnerable. However, the researchers are not in total agreement with this definition of an internet user as we believe that an individual can be younger than 16 years old and still uses or benefit from the internet. The definition of an internet user by Wei would be perfect in the situation that we classify internet users as those who are old enough to use internet on their mobile phones and computers [5]. These days, internet of things has changed the narratives of using internet on mobile devices to internet use in physical machines and infrastructures. In lieu of this our iconoclastic approach to defining who an internet user is, we define an internet user as any individual who uses the internet directly through mobile devices or indirectly through internet of things no matter how old in years.

Internet penetration has grown steadily in Africa in the last two decades as some countries in Africa are growing their netizens population geometrically. In the work of Männistö, Kelly, \& Petrazzini [2], titled internet status in Africa, they noted that internet penetration is growing poor in Africa excluding South Africa. This study showed that South Africa is the first country in Africa to have a massive internet penetration as far back as the early 90's. however, over a decade after this report, Africa has experienced a steady and impressive internet penetration in all the fibres of the society. Even though the level of penetration is not equal across the continent as some countries seems to be have more penetration than others but in a nutshell, Internet penetration in Africa, however slow is not what it used to be in 1997 when South Africa was topping the charts the champion of Internet in Africa. This slow penetration can however be attributed to a lot of challenges.

[1] stated various challenges militating against internet penetration in Africa. The most prominent of these challenges being high pricing. Others are insufficient international bandwidth, monopolistic market structures, lack of national backbones, low regional population density, adult literacy and lack of local contents. These challenges are indicative of the fact that Africa has faced so much in general technology adoption most especially in countries that still battles with stable electricity power supply. Addressing the high pricing component of this challenges, the report stated that Affordability is not a function of wealth alone, but also of pricing. It further explained that Internet pricing in Africa is prohibitively high adversely impacting affordability for even countries with higher per-capita incomes. For example, the lowest monthly broadband tariff in Burundi is over $7,000 \%$ of average monthly income, a price point that limits the addressable market to very niche segments. This confirms again that Burundi has the most expensive internet in the continent of Africa.

An empirical review of literature on internet penetration in Africa showed that since the start of this millennium, African countries have experienced a steady growth in Internet penetration from $0.78 \%$ in 2000 to $20.71 \%$ in 2014 [3]. This growth may seem small in the space of 14 years but it is still somewhat impressive for a continent that has faced myriads of infrastructural dwarfism. In other to appreciate the impressive growth of internet penetration in Africa, [3] further noted that while Africa still lags the rest of the world in Internet penetration, it is bridging the gap very quickly. For example, in 2005, Internet penetration in Europe was 19.6 times greater than that of Africa, but by 2014, it was only 3.9 times greater. An analysis of internet users in Africa based on the top 10 and bottom 10 countries in terms of GDP per capita showed that between 2001 and 2013, Burundi had the lowest number of internet users and Mozambique had 
the highest number of internet users in the bottom 10 countries category. In the category of top ten countries based on per capita income in Africa, Gabon had the lowest number of internet users while Egypt had the highest. This empirical data showed that Egypt overtook South Africa eventually overtime even though the first internet investment in Africa was made in South Africa in 1988 by Mark Lawrie followed by Ghana in 1933 by Nii Narku Quaynor.

According to Okae [4], Internet users in Africa use the internet for different reasons such as social media surfing, education, entertainment and accessing public services. In the survey by Okae, a larger percentage of the respondents confirmed that they used the internet for social media surfing as compared to other purpose of use. This is consistent with the results gotten from the respondent $s$ of this study on their purpose of use of internet as a larger percentage of the respondents chose social media surfing as the biggest purpose on the internet. This shows the desires of humans to connect and socialize even in an online environment. As it stands, the social media is becoming the new TV, radio and digital communication platforms as whole. Social media has accelerated information access, ecommerce and digital advertisements and these and many reasons have made many, young and old to tilt fully towards the use of social media. It should be noted that despite the many privacy issues conversation in the use of social media, the number of users of these new media increased every year since its mainstream acceptance especially Facebook that was introduced in 2004 and Twitter in 2006.

In conclusion, the review of literature has shown that there has been a steady growth in internet penetration in Africa even though there is a varying rate of penetration across countries. However, Rwanda seems not be included in almost all the global internet penetration report in Africa despite the impressive growth and development it has experienced post genocide. Rwanda has become a force to be reckoned with in Africa and a global attention must be paid to including its internet penetration ratio in subsequent reports based on the outcomes of studies like this and subsequent studies of this nature.

\section{Theoretical Framework}

\subsection{Thorstein Veblen's theory of Technology Determinism}

Thorstein Veblen's theory of technology determinism is in perfect alignment with the variables and ideological premise of this research. Technological determinism is a reductionist theory that aims to provide a causative link between technology and a society's nature. It tries to explain as to whom or what could have a controlling power in human affairs. The theory questions the degree to which human thought or action is influenced by technological factors.

A practical application of this theory to this study shows that internet penetration is the technology that is determining the opportunity search culture of young people in Rwanda. The Internet seems to be the determining factor that guarantees the career, educational and professional opportunities for young people in Rwanda. It will be pertinent to note that technology determinism theory creates a causative link and society's nature., It is not impossible that there is a circularly causal relationship between the internet and opportunity access. Furthermore, the theory explains to whom or what could have the controlling power in human affairs. In lieu of the aforementioned, this study will test this theory to see if the internet has actually become the ruler in the opportunity search for young people. The outcome of this test of theory will determine if there will be inductive theorizing about technology determinism in subsequent studies by the researcher on cases of similar variables.

\section{Methodology}

This is an Explanatory Sequential Mixed Method study. Qualitative data was collected through the use of a questionnaire of 100 randomly selected Rwanda youth and guided interviews were conducted for 10 selected undergraduate students of the African Leadership University in Kigali, Rwanda. Analysis of data was done using frequency counts and percentage ratings. Opinion analytics was used in interpreting and reporting interview responses.

\section{Data Analysis and Discussion}

\subsection{Quantitative Survey Discussion}

The questionnaire shared with the respondents asked questions on demographic characteristics and six other variable related questions. The responses are reported below based on each of the questions asked.

\subsection{Age of respondents}

In this context of study, young people refer to people between the ages of 18 years and 35 years of age. The result below shows that $86 \%$ of the respondents are between the ages of 20-29 years while $11.8 \%$ are between the ages of 15 - 19 years. These results give credence to the fact that the most active young people 
on the internet in Rwanda are between the ages of 2029 years A series of internet penetration indicators were used in measuring the level of internet penetration. The bar chart below shows that internet penetration has had the highest impacts in giving access to valuable data with a $70.7 \%$ outcome as compared to the other indicators. This is a confirmation of the importance of open data in decision making in the present digital economy. Data is the new oil and one of the most important roles of internet penetration is the access it gives to these open and re-usable data.

\section{Age \\ 93 responses}
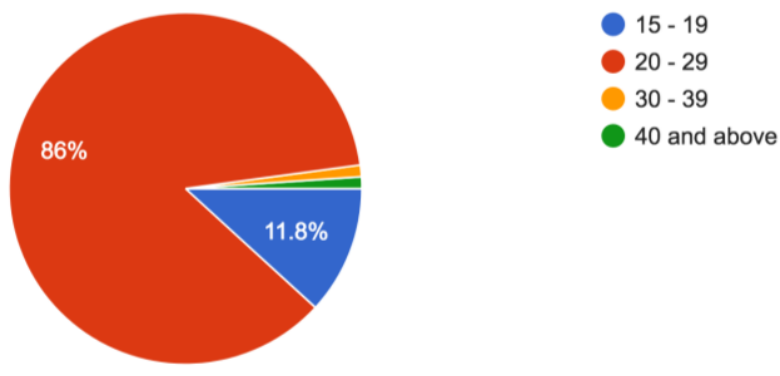

\subsection{Internet Penetration}

Internet penetration has helped Rwanda in developing e-commerce as $69.6 \%$ of the respondents noted. This is a close rank after access to data. It is very pertinent to note that access to data would invariably enable businesses to grow and build a base online. However, it is surprising to discover that internet penetration has not really influenced the tourism industry in Rwanda despite the efforts of the government to invest and develop the industry in the last 5 years. Tourism remains one of the best revenue streams for the government of Rwanda and this $1.1 \%$ result shows that there is a lot of potential from the use of the internet in promoting the tourism industry in the country. If the tourism industry is doing so well without the advantages of the internet, it can definitely do better with the use of the internet.

\section{Internet Penetration has helped Rwanda in the following ways (Pick as many choices as possible)}

92 responses

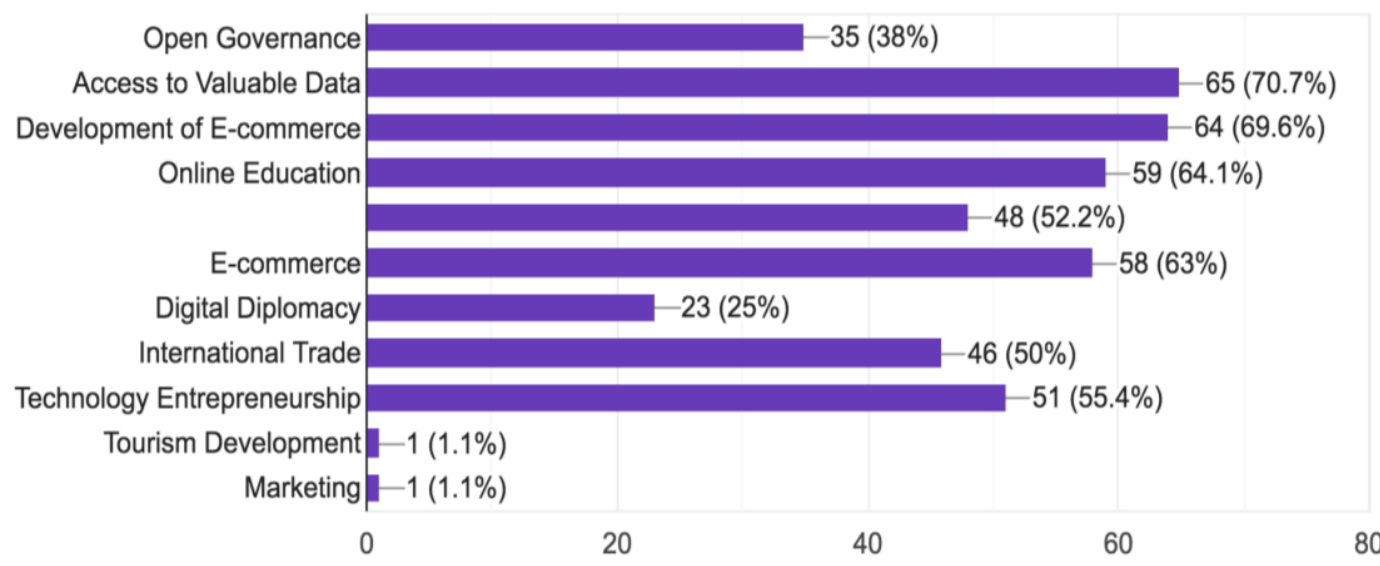




\subsection{Opportunities on the Internet}

It is no gainsaying that the internet has a lot of opportunities chronicled in it. The opportunities are so enormous that there have been discussions globally on information explosion. However, the opportunity one gets online is dependent on interests and abilities to search in the complex web environment. A high $76.6 \%$ of the respondents noted that the internet has given them foreign university admissions as well as research articles. This is indicative of the fact most young people between the ages of 20 and 29 years old are most likely students in search of higher education opportunities or in the university.

These are followed closely by a $66 \%$ response on searches for professional networks. This can be seen as one of the things needed by young people as most are looking for job opportunities and career prospects after graduation. This pushes them to make use of the internet to develop professional networks to tap into any time they are in need of such.

\subsection{Offline and online opportunities}

It has been observed through observations and research articles that most young people prefer to look online for opportunities than offline opportunities. This is a testament to the notion that offline opportunities end up online in some future date to provide access to masses. In this study, $55.2 \%$ of the respondents disagreed that there are more opportunities offline which invariably means they believe there are more opportunities online than offline. Additionally, the results indicated $32.3 \%$ respondents are not sure or rather in-between the two divides while $12.5 \%$ believed that there are more opportunities offline than online.

A cross-examination of this result with the guided interview puts a second-year entrepreneurship student (IP/006/ENT), in the $12.5 \%$ group who believed that there are more opportunities offline than online. To this group, whether there is internet or not, they will always reach the peak of their potential by searching for opportunities through offline channels either from friends, colleagues, family members and professional connections.

\title{
2. What are the opportunities you have gotten with the use of the internet? (Pick as many choices as possible)
}

\author{
94 responses
}

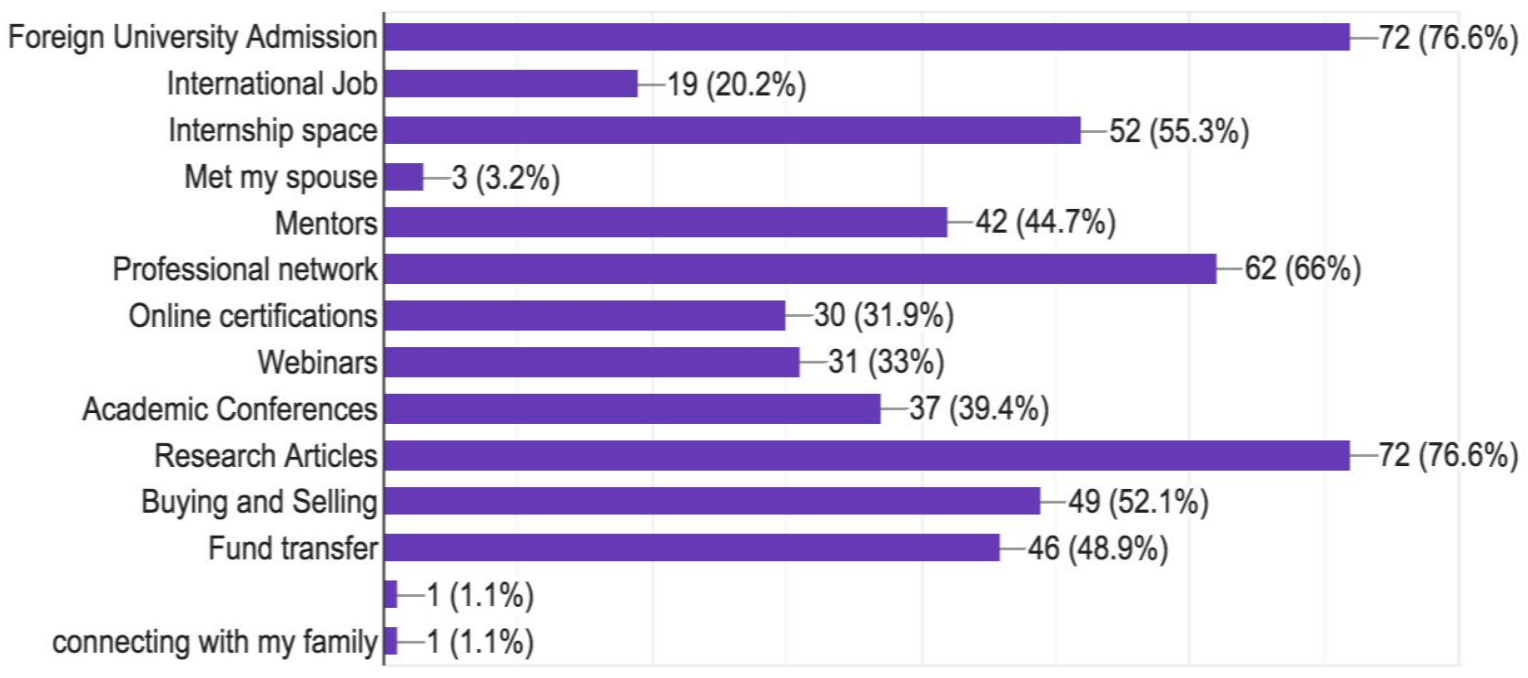

0

20

40

60

80 


\section{There are more opportunities offline than online}

\section{6 responses}

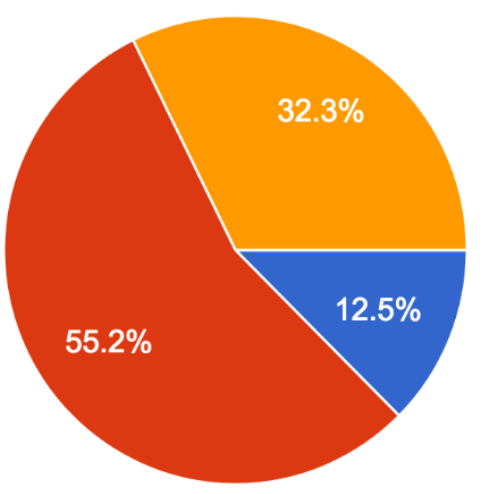

Yes

No

Maybe

\subsection{Time spent on the internet per day}

light of this, respondents were asked the average time they spend on the internet daily. Surprisingly $78.1 \%$ of

The 21 st century has become so tech-deterministic that netizens must always do something on the internet.... Our lives are becoming more and more dependent on the services that are on the internet. In the respondents indicated spending 5 hours and above daily on the internet. The results in this study apply to simpler studies globally.. This is the reality of the age we live in as internet penetration evolves every day across various industries and societies.

\section{Average hour spent on the Internet per day}

\section{6 responses}

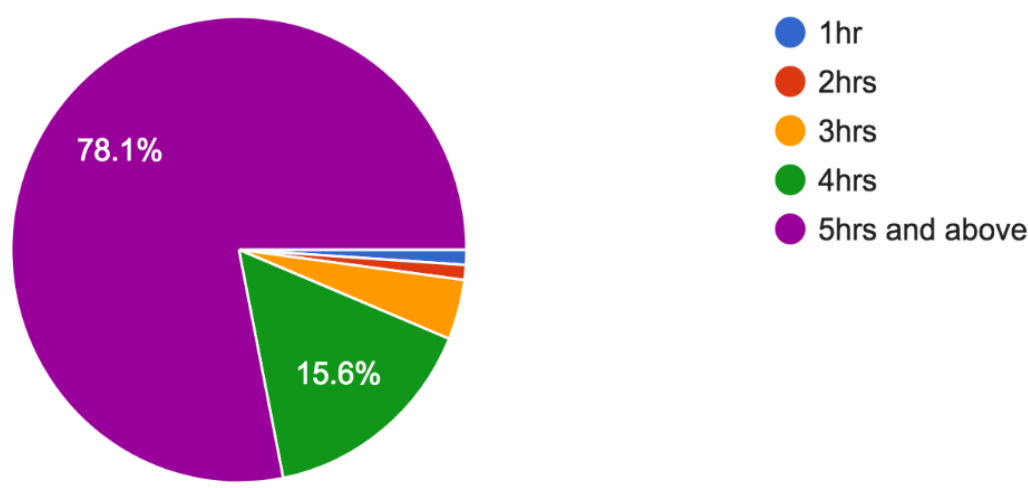




\section{I am doing the following when I am online(You can pick more than one choice)}

95 responses

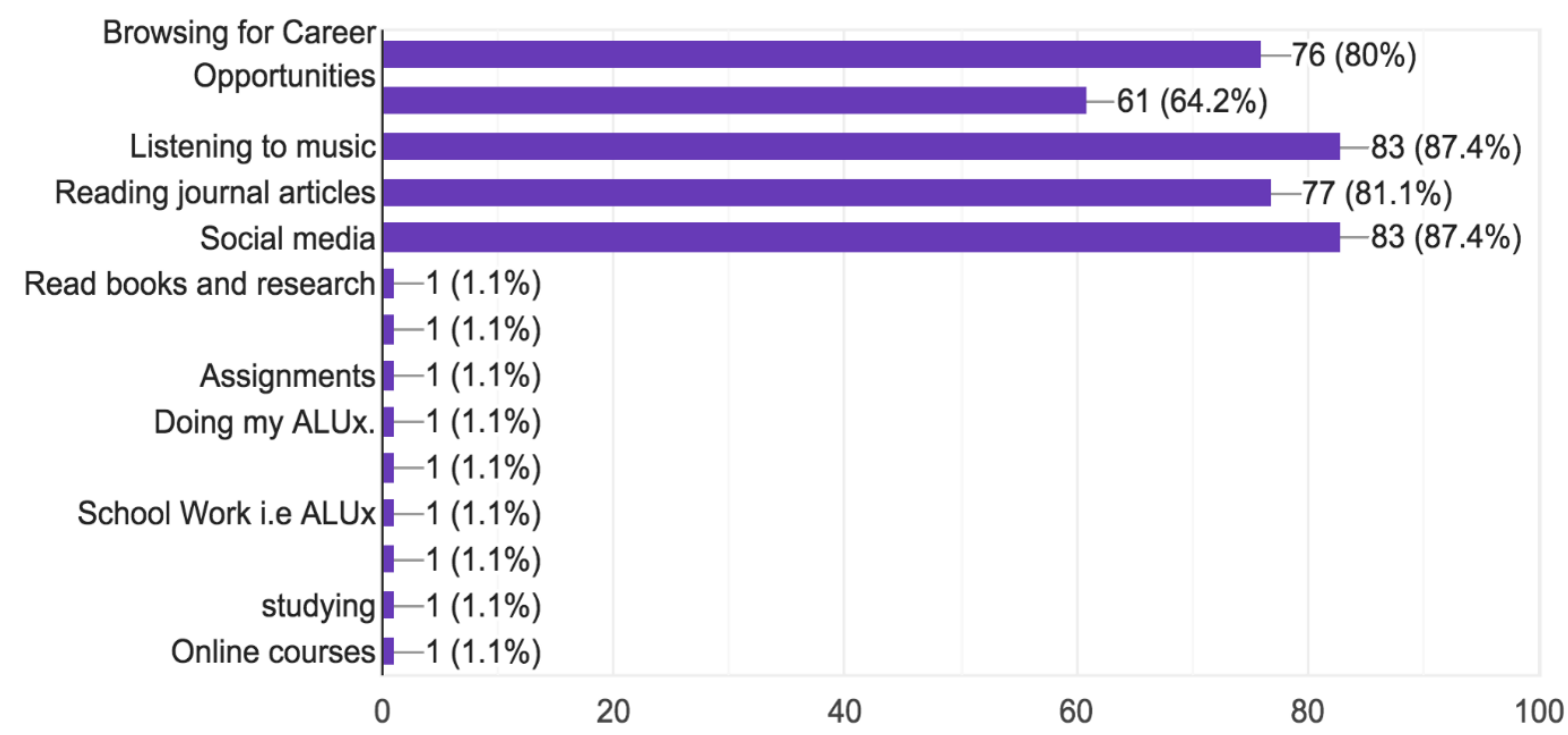

\section{Which of these websites do you use most when you are looking for opportunities(You can pick more than one choice)}

94 responses

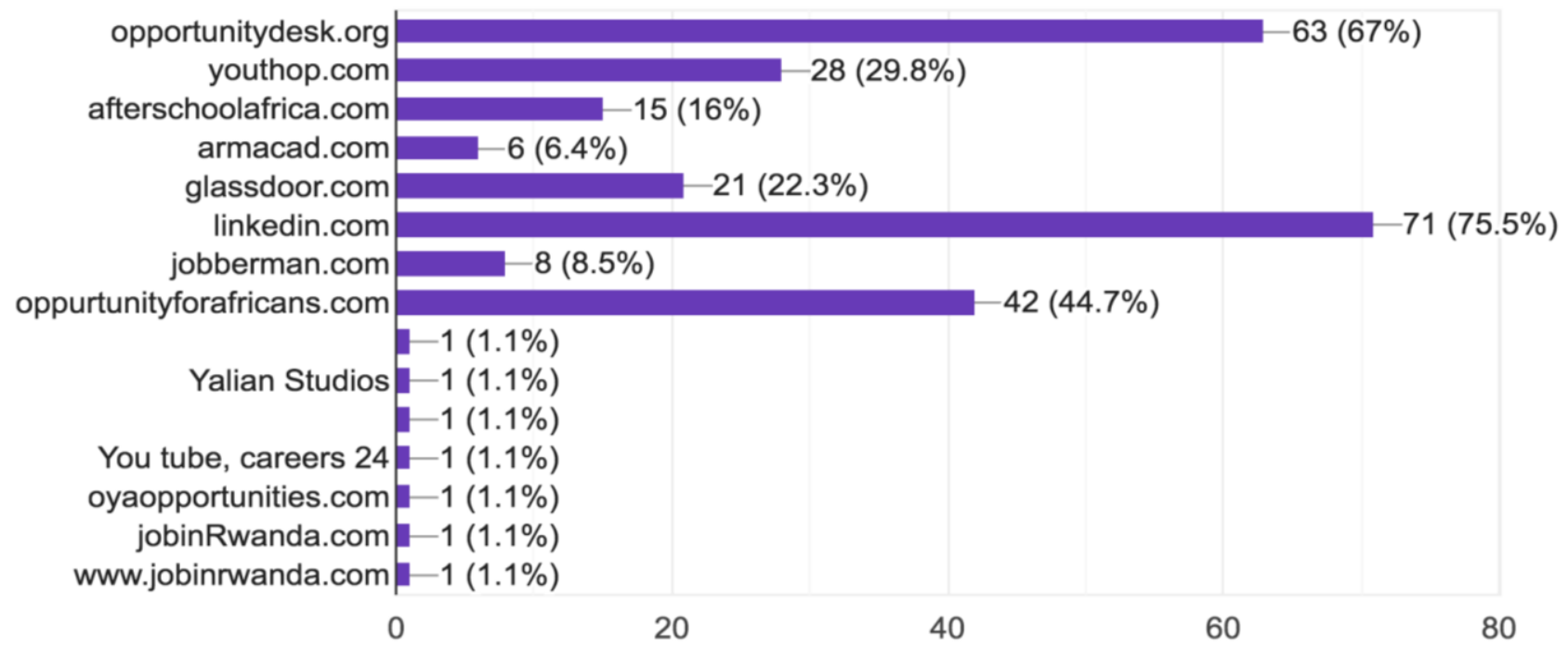




\subsection{Activities engaged in online}

It is very pertinent to note that there are many activities, services, and tools to explore on the internet. The respondent's priorities online seemed to show in their responses as a higher percentage of $87.4 \%$ stated that they are either listening to music or browsing social media most of the time.

This result can help in generating insights into the potential for the entertainment industry in Rwanda as well as technology startups to develop live online music streaming platforms for young people. The government can also take advantage of this opportunity to intensify and consolidate on its electronic government initiatives by using social media to engage the youth.

The youth are also searching for career opportunities as $80 \%$ noted that they are online most times to search for career opportunities. This is consistent with the result that showed a higher percentage of the respondents agreed that there are more opportunities online.

\subsection{The websites used in searching for opportunities}

The web contains a myriad of websites and portals to search for opportunities. A higher percentage of the respondents, $75.5 \%$ chose LinkedIn to be their go-to website for opportunities. This is followed by $67 \%$ who chose opportunitydesk.org as their go-to website for opportunity search. Opportunityforafricans.com ranked third as $44.7 \%$ chose it as their go-to website for opportunity search

\section{Guided Interview Discussion}

Ten undergraduate students were interviewed with an interview guide that asked the following question;

1. Where do you prefer to search for opportunities?

2. What are the websites you browse online for opportunities?

3. What are some of the opportunities have you obtained online since you started using the internet to search for opportunities?

The question of preference on where to look for opportunities elicited a lot of responses from the respondents. A second-year global challenges student (IP/001/GLC) said;

"I used to look for information offline in the past especially when I was looking for admission information to the universities of my dreams but I figured out that most people hoard information and of those who gave me information, there were a lot of lies and distortion in information given to me. It was not long after then that I discovered that I could actually get the right information I needed online from the websites of the Universities I wanted. Online opportunities brought me to the African Leadership University and I can boldly say that I never needed anybody's help to make my applications. The internet is truly a great domain for opportunities for those who can search"

A deep opinion analysis of this student's response shows that with a proper orientation about online sources, young people can get opportunities without any external help or information as long as they follow the instructions of the application. Website surfing of specific organization can lead to the discovery of information about opportunities that might be on the open web for easy discovery. This could mean that there is a need for a deliberate decision to always visit websites of organizations where opportunities are being sought.

Another second-year computer science student, (IP/002/CPS) was asked to list the websites he browses when he is searching for opportunities. He had these to say;

"I discovered www.opportunitydesk.org in one of my many online searches and I have consistently visited it every single day since 2017. To corroborate this, a first-year student $(I P / 003 / L D C)$ noted that she uses www.afterschoolafrica.com for all her opportunity searches and she has gotten two fully sponsored social entrepreneurship trips from the platform. Another first-year student, (IP/004/LDC) said he uses www.armacad.com for his opportunity searches as he traveled out of Africa for the first time because of a fully sponsored conference she discovered from this platform".

A student who was more research centered in his opportunity search stated that;

"I use job euraxess, a European opportunity website to search for most of my research and educational opportunities. (IP/005/IBT)

He further answered the question of the kind of opportunities he has gotten from this platform. He was glad to answer that his first ever international youth forum trip was gotten from this platform. He also gave an explanation on how he got his first ever academic paper published in an international journal through a piece of information he read from job euraxess.

Deep opinion analytics of all these responses shows consistently that opportunities abound on the 
internet for those who know how to search. These responses are also a testament to the fact that young people are tilting towards opportunities on the internet more than any time in history.

A second-year Entrepreneurship student (IP/006/ENT) had a different opinion from all the responses above that have been consistent on the enormous opportunities that exist online. When asked where she prefers to look for opportunities, she responded with the following lines;

"I prefer offline opportunity searches through my family and friends network. These give direct access to the source of the opportunity and I am able to speak directly to those who could help me get the opportunity through physical conversations. I cannot count the number of opportunities I have applied for on the internet without any response or acknowledgment of application. I sometimes feel I am wasting my team online after applying for opportunities without responses. This has unconsciously pushed towards offline information hunting and it has worked very well for me"

\section{Conclusion}

This study has been able to answer a few questions on the roles of internet penetration on opportunity search by the young people of Rwanda. This study has shown vividly that the youths in Rwanda are online and use more of social media and music websites when they are online.

In terms of opportunity search, this study has revealed that most Rwandan youths prefer to use LinkedIn to search for opportunities followed by opportunitydesk.org. In addition, a larger percentage of them believed that there are more opportunities online than offline and confirms that Rwandan youths are exploring more online channels for their opportunities. The opportunities that internet penetration has brought to the society are enormous and the youths in every society must make use of these opportunities to further accelerate growth and progress in many aspects of their lives.

\section{Policy Recommendations}

This study has generated a lot of insights for policy arena in Rwanda:

1. It has been observed from this study that the level of digital diplomacy is very low in Rwanda. Internet penetration is an opportunity for the government to enact new policies that make Rwanda relevant in the global.

2. Digital diplomacy pool.

3. A larger percentage of Rwandan young people are on social media. This is an opportunity for the government to make news policies on electronic governance and participatory governance that engages the young people online.

4. This study has shown that internet penetration has helped Rwanda to provide valuable data to its citizens. This is an opportunity to make policies on Open data and plan towards becoming a leader in open data initiatives in Africa.

5. This study has revealed that most young people are listening to music online. This is a great opportunity for the government to make policies that will accelerate the entertainment industry. This will not only boost the economy but will also be a good strategy for the country with the fastest growing economy in Africa.

\section{References}

[1] Insights, T. and M. (2009). Anticipating Internet Growth in Africa. Capgemini, (41).

[2] Männistö, L., Kelly, T., \& Petrazzini, B. (1997). Internet status in Africa. From TamTam to Internet, ITU, (September), 1-14.

[3] Nyirenda-Jere, T., \& Biru, T. (2015). Internet Development and Internet Governance in Africa. Internet Society, (May), 1-44. Retrieved from http://www.internetsociety.org/sites/default/files/Internet development and Internet governance in Africa.pdf

[4] Okae, P. (2009). Réunions. Structure, (April). https://doi.org/10.5923/j.computer.20130302.02

[5] Wei, J. (2005). Internet Penetration Analysis: The Impact on Global E-Commerce. Data Base, 13(1), 9-24. 